\title{
Wildervanck or cervico-oculo-acoustic syndrome and MRI findings
}

\author{
P J Hughes, P T G Davies, S W Roche, T D Matthews, R J M Lane
}

In 1952, Wildervanck ${ }^{1}$ described the first case of what he styled the cervicooculo-acoustic (COA) syndrome. This comprises Klippel Feil's (KF) anomaly (congenitally fused cervical vertebrae), congenital sensorineural deafness and Duane's retraction syndrome ${ }^{2}$ (deficient abduction with retraction on adduction). Since that original paper, there have been further reports describing this triad, either completely or incompletely. A further case of this syndrome is reported and the first report of MRI head scan findings in this condition is presented. In addition, the origin of mirror movements observed as part of the KF syndrome are discussed.

\section{Case Report}

A 50 year old woman was admitted for the further evaluation of episodic right-sided facial weakness, associated with vague head pains. She had been well until March 1988, when she began to experience increasing tinnitus and deafness in her right ear. Two months later, she presented with sudden onset of right sided weakness which included the face. A CT head scan revealed a lacunar infarct in the left corona radiata, poorly pneumatised left mastoid air cells and generalised atrophy of the posterior fossa structures including the brainstem, with a large fourth ventricle. Her right sided weakness improved substantially but she developed further intermittent episodes of mild right-sided facial weakness and vague head pains. By the time she was seen in our unit, these symptoms had resolved completely and her only spontaneous complaint was of increased stiffness of the right arm.

The patient was known to have had abnormal eye movements since birth and was found to be completely deaf in the left ear on a ruutine school hearing examination at the age of 12. There was no other history of note. There was a family history of vascular disease; her mother had two cerebrovascular accidents (CVA), the first in her 60s and one of her brothers had died of a myocardial infarct at the age of 38. The patient had smoked at least 20 cigarettes a day before her CVA.

On examination, the patient was of short stature $(1.47 \mathrm{~m})$ with the clinical features of the KF syndrome. The general medical examination was otherwise unremarkable. She had bilateral Duane's syndrome, with absent abduction, retraction on adduction and narr- owing of the palpebral apertures. She was orthotropic in the primary position and did not have diplopia. The oculo-cephalic reflexes on lateral gaze were absent but preserved small amplitude opticokinetic nystagmus (OKN) was found. Up-gaze was normal, but downgaze was impaired although OKN was present. She was unable to converge. She had minimal right facial weakness and was totally deaf in the left ear, but hearing appeared to be relatively preserved in the right ear on bedside testing. The only abnormalities in the limbs were an increase in tone of the right arm, and mirror movements.

The combination of physical signs supported a diagnosis of Wildervanck's syndrome, and an unrelated resolved right hemiparesis secondary to lacunar infarction. A repeat CT head scan did not reveal any change, four vessel aortic arch digital subtraction angiography demonstrated no significant pathology and an echocardiogram was normal. A full haematological and biochemical screen was normal. Pure tone audiometry confirmed complete deafness in the left ear, but also showed mixed high frequency loss in the right ear. A cervical spine radiograph revealed extensive developmental abnormalities in the upper and mid cervical spine extending down to $\mathrm{C} 6$ compatible with the KF anomaly. An MRI head scan (fig) showed marked atrophy of the brain stem from the pons to the medullary cervical junction. There was a lesion measuring 1-2 $\mathrm{mm}$ in diameter in the pons to the left of the midline consistent with an infarct: the previously observed corona radiata infarct was not visible. The cerebellum was smaller than normal and the fourth ventricle was correspondingly dilated. There was failure of segmentation of the bodies of $\mathrm{C} 3$ and $\mathrm{C} 4$ with marked basilar invagination more pronounced to the left of the midline with indentation of the atrophied brain stem anteriorly.

\section{Discussion}

Hearing loss with KF anomaly, and hearing loss with an abducens nerve palsy had been documented $^{3}$ before Wildervanck reported the triad of signs which now bears his name. There is a gradual transition in the clinical features between complete and incomplete forms of COA syndrome. Only one third of patients with KF anomaly have hearing impairment and this may be purely conductive, sensorineural or mixed. ${ }^{4}$ In COA syndrome, the unilateral or bilateral congenital 
Figure MRI scan demonstrating marked cerebellar and brain stem atrophy with basilar invagination and failure of vertebral segmentation.

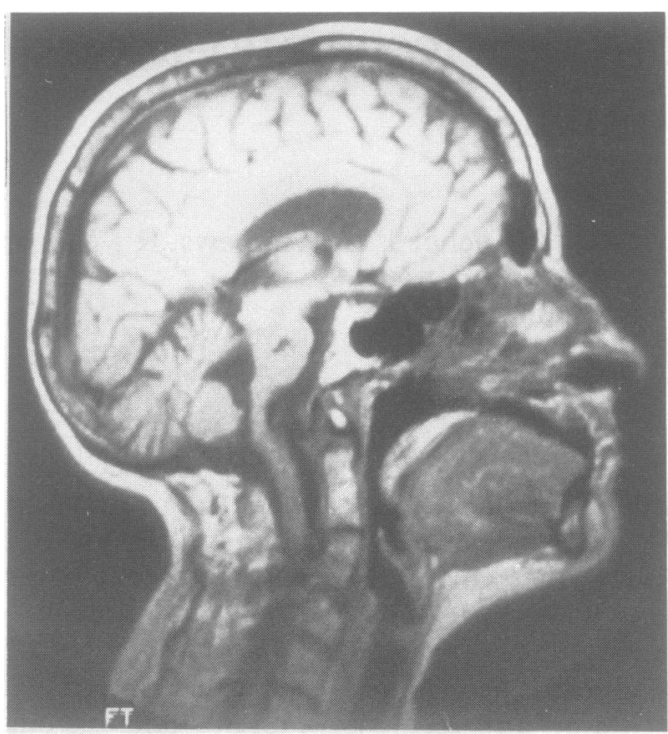

hearing loss is usually severe and of neurosensory origin though mixed hearing loss has been reported. ${ }^{4}$ The KF syndrome may overlap with the stigmata of COA, ${ }^{5}$ Turner's $^{6}$ and Noonan's ${ }^{7}$ syndromes and Wildervanck's syndrome is the most common multiple congenital abnormality found in association with Duane's syndrome. ${ }^{8}$ There is a tenfold female preponderance ${ }^{9}$ in COA syndrome. The cause is unknown, but Wildervanck ${ }^{9}$ suggests that it is due to polygenic heredity with sex limitation to the female, though $\mathrm{McKusick}{ }^{10}$ raises the possibility of sex linked dominance with fatal effect in the male. Chromosomal analysis has revealed normal patterns in females. ${ }^{11} \mathrm{~A}$ chromosome ring was demonstrated in one case $^{12}$ though this may have been the consequence of pre-natal radiation exposure.

There are few complete cases of COA syndrome in the British literature. We report a further case which exhibited all the features of this syndrome. This is the first report to include MRI changes showing marked cerebellar and brain stem atrophy with basilar invagination and failure of vertebral segmentation. Our patient also demonstrated prominent mirror movements and has been investigated extensively with regard to the pathogenesis of this phenomenon. Necropsy of a patient with KF anomaly and mirror movements revealed failure of pyramidal decussation in the cervical cord. ${ }^{13}$ This would leave little direct connection between the motor cortex of each hemisphere and its respective contralateral spinal cord. To generate movement of the contralateral extremities, the use of less specific alternate pathways such as those originating in the supplementary motor cortex would be required, and these would presumably give rise to bilateral activity. ${ }^{14}$ This case, however, was associated with cerebellar tonsil herniation and lack of fusion of the dorsal halves of the neural plate. Our patient did not have MRI evidence of such abnormalities and the left corona radiata infarct associated with right sided pyramidal signs provided evidence for pyramidal tract decussation. Electromyographic (EMG) recordings were made from both upper limb muscles and the results were compared with those obtained in normal control subjects. ${ }^{15}$ Liminal percutaneous electrical or magnetic brain stimulation applied over either hemisphere elicited bilateral and symmetrical short latency muscle responses in relaxed intrinsic hand muscles in our patient, while in normal subjects, unilateral brain stimulation only elicited contralateral muscle responses. Cross correlation analysis of ongoing single and multiunit needle EMGs recorded between muscles of left and right hands revealed a central peak in the cross-correlogram. ${ }^{15}$ No cross-correlogram peaks were found between left and right hand muscles in normal subjects. The number and time course of the central peaks in the cross-correlograms constructed between the firing of motor units on opposite sides of the body in the patient were similar to those found in cross-correlograms constructed between the firing of motor units from muscles on the same side of the body in the patient and in normal subjects. We concluded that the mirror movements in our patient resulted from motor commands that are distributed to motor neuron pools on the left and right side of the spinal cord via abnormally branched fast-conducting corticospinal tract fibres. The finding of bilateral long latency components of the cutaneous reflex in our patient strengthens the view that these components result from activity in a transcortical reflex pathway. ${ }^{1516}$

1 Wildervanck LS. Een geval van aandoening van KlippelFeil gecombineerd met abducensparalyse, retractio bulbi Feil gecombineerd met abducensparalyse, retractio

2 Duane A. Congenital deficiency of abduction associated with impairment of adduction, retraction movements, contraction of the palpebral fissure and oblique movements of the eye. Arch ophthalmol 1905;34:133-59.

3 Koningsmark BW, Gorlin RJ. Genetic and metabolic deafness. Philadelphia: W B Saunders, 1976.

4 Cremers CWRJ, Hoogland GA, Kuypers W. Hearing loss in the cervico-oculo-acoustic (Wildervanck) Syndrome. Arch Otolaryngol 1984;110:54-7.

5 Gorlin RJ, Pindborg JJ, Cohen MM. Syndromes of the head and neck. New York: McGraw-Hill Book Co, 1976.

6 Anderson H, Filipson R, Flurr E, Kock B, Lindsten J Wedenberg E. Hearing impairment in Turner's syndrome. Acta Otolaryngol 1969, suppl 247.

7 Cremers CWRJ. Hearing loss in Noonan's syndrome. $J$ Pediatr 1976;88:363.

8 Pfaffenbach DD, Cross HE, Kearns TP. Congenital anomalies in Duane's retraction syndrome. Arch ophtholmol 1972:88:635-9.

9 Wildervanck LS. The cervico-oculo-acusticus syndrome. Congenital malformations of the spine and spinal cord. In Vinken PJ, Bruyn CW, eds. Handbook of clinical neurology. Amsterdam: North Holland, 1978.

0 McKusick VA. Mendelian inheritance in man. Baltimore: Johns Hopkins, 1971

1 Palant DI, Carter BL. Klippel-Feil syndrome and deafness. Amer J Dis Childh 1972;123:218-21.

12 Fraser WI, MacGillivray RC Cervico-oculo-acoustic dysplasia (The "Syndrome of Wildervanck"). J Ment Defic Res 1968;12:322-9.

13 Gunderson CH, Solitare GB. Mirror movements in patients with the Klippel-Feil syndrome. Arch Neurol 1968;18:675-9.

14 Brock S, Krieger HP. The Basis of clinical neurology. Baltimore: Williams and Wilkins, 1963

15 Farmer SF, Ingram DA, Roche SW, Stephens JA. Evidence that mirror movements in the Klippel-Feil syndrome in man are produced by activity in branched-stem presynaptic inputs from cortico-spinal neurones. J Physiol 1989;418:102.

16 Farmer SF, Ingram DA, Stephens JA. Mirror movements studied in a patient with Klippel-Feil syndrome. J Physiol 1990;428:467-84 